\title{
OPEN DNA metabarcoding of fungal diversity in air and snow of Livingston Island, South Shetland Islands, Antarctica
}

Luiz Henrique Rosa ${ }^{1 \bowtie}$, Otávio Henrique Bezerra Pinto ${ }^{2}$, Tina Šantl-Temkiv ${ }^{3}$, Peter Convey ${ }^{4}$, Micheline Carvalho-Silva ${ }^{5}$, Carlos Augusto Rosa ${ }^{1}$ \& Paulo E. A. S. Câmara ${ }^{5}$

We assessed fungal diversity present in air and freshly deposited snow samples obtained from Livingston Island, Antarctica, using DNA metabarcoding through high throughput sequencing (HTS). A total of $740 \mathrm{~m}^{3}$ of air were pumped through a $0.22 \mu \mathrm{m}$ membrane. Snow obtained shortly after deposition was kept at room temperature and yielded $3.760 \mathrm{~L}$ of water, which was filtered using Sterivex membranes of $0.22 \mu \mathrm{m}$ mesh size. The total DNA present was extracted and sequenced. We detected 171 fungal amplicon sequence variants (ASVs), 70 from the air and 142 from the snow. They were dominated by the phyla Ascomycota, Basidiomycota, Mortierellomycota and Mucoromycota. Pseudogymnoascus, Cladosporium, Mortierella and Penicillium sp. were the most dominant ASVs detected in the air in rank order. In snow, Cladosporium, Pseudogymnoascus, Penicillium, Meyerozyma, Lecidea, Malassezia, Hanseniaspora, Austroplaca, Mortierella, Rhodotorula, Penicillium, Thelebolus, Aspergillus, Poaceicola, Glarea and Lecanora were the dominant ASVs present. In general, the two fungal assemblages displayed high diversity, richness, and dominance indices, with the assemblage found in snow having the highest diversity indices. Of the total fungal ASVs detected, 29 were only present in the air sample and 101 in the snow sample, with only 41 present in both samples; however, when only the dominant taxa from both samples were compared none occurred only in the air and, among the rare portion, 26 taxa occurred in both air and snow. Application of HTS revealed the presence of a more diverse fungal community in the air and snow of Livingston Island in comparison with studies using traditional isolation methods. The assemblages were dominated by cold-adapted and cosmopolitan fungal taxa, including members of the genera Pseudogymnoascus, Malassezia and Rhodotorula, which include some taxa reported as opportunistic. Our results support the hypothesis that the presence of microbiota in the airspora indicates the possibility of dispersal around Antarctica in the air column. However, further aeromycology studies are required to understand the dynamics of fungal dispersal within and beyond Antarctica.

Antarctica represents one of the most pristine regions of the planet and, despite the multiple extreme conditions that characterize it, harbours a considerable terrestrial biodiversity, mainly of microorganisms, that are able to survive and colonize its different environments. Due the continent's isolation from lower latitudes by the oceanic Antarctic Circumpolar Current and atmospheric circulation, the lack of trophic complexity, and the vulnerability of its endemic biodiversity to environmental changes and anthropogenic influences, Antarctica provides a unique opportunity for microbial aerobiology studies seeking to understand how airspora are transported to and within Antarctica ${ }^{1,2}$. The extent to which Antarctic environments receive microbial propagules, potentially including globally cosmopolitan species from outside Antarctica, remains largely unstudied, although they have been detected in the air column and after deposition, for instance in snow and ice ${ }^{3-7}$. According to Archer et al. ${ }^{2}$, microbial communities present in ecosystems of isolated regions of Antarctica, such as the Victoria Land Dry

${ }^{1}$ Laboratório de Microbiologia Polar e Conexões Tropicais, Departamento de Microbiologia, Instituto de Ciências Biológicas, Universidade Federal de Minas Gerais, P.O. Box 486, Belo Horizonte, MG CEP 31270-901, Brazil. 'Departamento de Biologia Celular, Universidade de Brasília, Brasília, Brazil. ${ }^{3}$ Department of Bioscience, Aarhus University, Building 1540 Office 124, 116 Ny Munkegade, 8000 Aarhus C, Denmark. "British Antarctic Survey, NERC, High Cross, Madingley Road, Cambridge CB3 OET, UK. ${ }^{5}$ Departamento de Botânica, Universidade de Brasilia, Brasília, Brazil. ${ }^{\boxplus}$ email: Ihrosa@icb.ufmg.br 


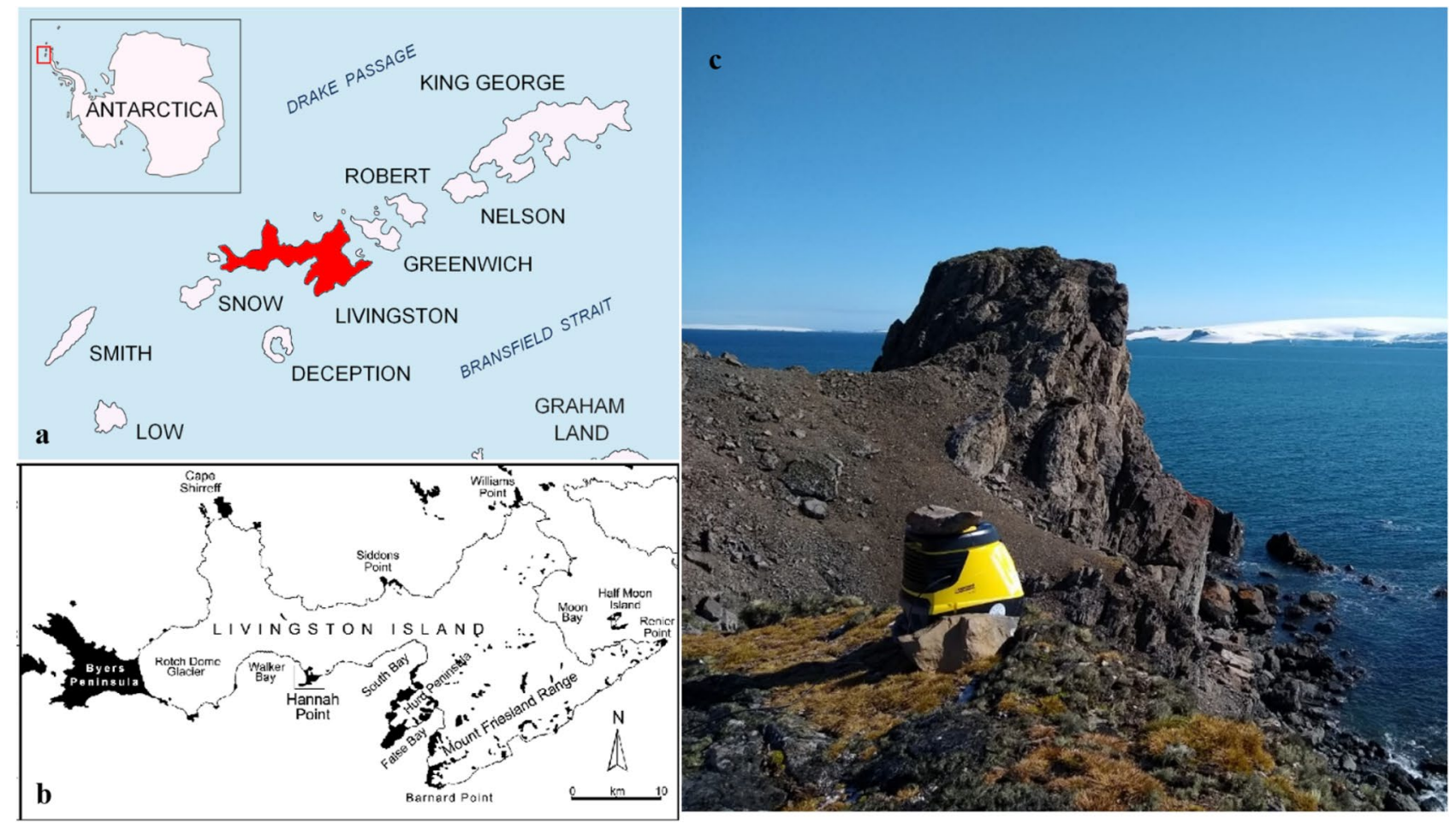

Figure 1. Location of soil sample collections. (a) Antarctic Peninsula, (b) Livingston Island and (c) Punta

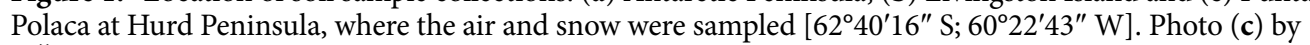
T Šantl-Temkiv.

Valleys, display limited connectivity to the global microbial pool due the strong selection that occurs during atmospheric transport, resulting in regionally isolated airborne inputs and highly specialized soil communities, with fungi also displaying greater isolation from non-polar sources than bacteria. However, detailed information about the aerial routes by which microorganisms arrive and circulate in Antarctica is lacking ${ }^{8,9}$.

Biological dispersal by aerial means can be an important factor shaping patterns of biodiversity ${ }^{9,10}$. Viable organisms or their propagules present in the air column may be in dormant and cryptobiotic states, where they are metabolically inactive due the harsh dry, cold, low nutrient and high irradiance conditions. Diverse groups of microorganisms have been recorded in the few Antarctic aerobiological studies completed to date (reviewed by Pearce et al. ${ }^{9}$ ), including viruses, bacteria, microalgae and fungi.

Mycological studies in Antarctica have shown that much of the Antarctic fungal community is represented by cold tolerant (psychrophilic or psychrotolerant) species, many of which have wide and even globally cosmopolitan distributions, with presence in polar, temperate, and tropical environments ${ }^{11}$. de Menezes et al. ${ }^{12}$ suggested that the high densities of cosmopolitan fungi present in snow are consistent with them being present in air masses arriving at the Antarctic Peninsula from beyond Antarctica, which are then entrained in snow precipitation, and become concentrated in the snow. Snow and ice can provide an indirect record of the presence and deposition of fungal propagules (e.g. spores or hyphal fragments) from the air column over time ${ }^{12}$. In snow samples obtained from six different regions of the Antarctic Peninsula, de Menezes et al. ${ }^{13}$ reported a rich fungal diversity assigned to 51 species in 26 genera and dominated by cold tolerant cosmopolitan fungi. However, in ice from continental Antarctica and the Antarctic Peninsula, Rogers et al. ${ }^{14}$ and de Menezes et al. ${ }^{15}$, respectively, reported much lower fungal diversity. In the present study, we assessed fungal diversity present in air and freshly deposited snow samples obtained from Livingston Island, Antarctica, using DNA metabarcoding through high-throughput sequencing (HTS).

\section{Material and methods}

Snow and air sampling. Air and snow samples were collected at Punta Polaca $\left(62^{\circ} 40^{\prime} 16^{\prime \prime}\right.$ S; $\left.60^{\circ} 22^{\prime} 43^{\prime \prime} \mathrm{W}\right)$, Hurd Peninsula, Livingston Island, South Shetland Islands, near to the Spanish station Juan Carlos I (Fig. 1). Two air samples were collected with a high flow glass impinger following Šantl-Temkiv et al. ${ }^{16,17}$. The chamber was filled with $2 \mathrm{~L}$ of sampling liquid $\left(\mathrm{ddH}_{2} \mathrm{O}\right)$ and the sampler was run for $5 \mathrm{~min}$, so that the liquid came in contact with the entire chamber, after which $0.5 \mathrm{~L}$ of the sampling liquid was removed, stored as a control, and analyzed along with the samples. The control represented a field blank to certify that the samples were not contaminated by external organisms. The resulting solution was filtered directly on the Sterivex filter units for the air, as described by Lever et al. ${ }^{18}$. Air was collected over c. 5 h on March 11th 2019. In addition, the two separate air DNA extractions were combined together in order to increase DNA yield. Two freshly deposited snow samples were collected on March $20^{\text {th }} 2019$ at the same site using a sterilized shovel. Both pairs of samples were separately 
combined in order to increase DNA yield. Snow was melted at room temperature, under strictly sterile conditions, for $24 \mathrm{~h}$ in the laboratory at Juan Carlos I Station and then filtered using Sterivex filters ${ }^{18}$.

DNA extraction and data analysis. Total DNA was extracted from environmental samples using the Qiagen Power Soil Kit (Qiagen, USA) following the manufacturer's instructions. Extracted DNA was used as template for generating PCR amplicons. The internal transcribed spacer 2 (ITS2) of the nuclear ribosomal DNA was used as a DNA barcode for molecular species identification ${ }^{19,20}$. PCR amplicons were generated using the universal primers ITS3 and ITS $4^{21}$ and were sequenced by high-throughput sequencing at Macrogen Inc. (South Korea) on an Illumina MiSeq sequencer, using the MiSeq Reagent Kit v3 (600-cycle) following the manufacturer's protocol.

Raw fastq files were filtered using BBDuk version 38.34 (BBMap-Bushnell B.-sourceforge.net/projects/ bbmap/) to remove Illumina adapters, known Illumina artifacts, and PhiX Control v3 Library. Quality read filtering was carried out using Sickle version 1.33-q 30-1 5022, to trim ends 3' or 5' with low Phred quality score. Sequences shorter than 50 bases were discarded. These sequences were imported to QIIME2 version 2019.10 (https://qiime2.org/) for bioinformatics analyses ${ }^{23}$. The qiime2-dada2 plugin is a complete pipeline that was used for filtering, dereplication, turning paired-end fastq files into merged reads, and removal of chimeras ${ }^{24}$. Taxonomic assignment was carried out for the amplicon sequence variants (ASVs) using qiime2-feature-classifier ${ }^{25}$ classify-sklearn against the UNITE fungal ITS database version $7.2^{26}$ and trained with Naive Bayes classifier. A confidence threshold of $98.5 \%$ was used. All raw sequences have been deposited in the NCBI database under the codes SRR12830238, SRR12830240 and SRR12830239.

Many factors, including extraction, PCR, and primer bias, can affect the number of reads ${ }^{27}$, and thus lead to misinterpretation of abundance ${ }^{28}$. However, Giner et al. ${ }^{29}$ concluded that such biases did not affect the proportionality between reads and cell abundance, implying that more reads are linked with higher abundance ${ }^{29,30}$. Therefore, for comparative purposes we used the number of reads as a proxy for relative abundance.

All sequences obtained from air and snow samples were matched with sequences present in the list of the top 50 'most wanted' fungi according to Nilsson et al. ${ }^{31}$. The sequences were merged, filtered, dereplicated, and clustered into $>97 \%$ identity ASVs using USEARCH version $10^{32}$. Nucleotide-Nucleotide BLAST 2.6.0 + was used to compare these ASVs against the top50_release_04.02.2020.fasta ${ }^{33}$, considering just subject matches with aligned length longer than $250 \mathrm{bp}$ and $>98 \%$ identity.

Fungal diversity and distribution. To quantify species diversity, richness, and dominance, we used the following indices: (i) Fisher's $\alpha$, (ii) Margalef's, and (iii) Simpson's, respectively. The numbers of DNA reads of the amplicon sequence variants (ASVs) were used to quantify the fungal taxa present in the air sampled, where fungal ASVs with more than 1,000 reads were considered dominant and $<1,000$ minor components (rare) of the fungal community. All of the results were obtained with $95 \%$ confidence, and bootstrap values were calculated from 1,000 iterations. Taxon species accumulation curves were obtained using the Mao Tao index. All diversity indices and species accumulation curves calculations were performed using PAST v. $1.90^{34}$. Venn diagrams were prepared according to Bardou et al. ${ }^{35}$ to compare the fungal assemblages present in both air and snow samples. The functional assignments of fungal ASVs at species and genera levels are shown using FunGuild ${ }^{36}$.

\section{Results}

Fungal taxonomy. The number of reads in the air sample was 162,038 and that in snow 268,710. From these, we detected 171 fungal amplicon sequence variants (ASVs), 70 in $740 \mathrm{~m}^{3}$ of air and 142 in $3.76 \mathrm{~L}$ of snow from Livingston Island, Antarctica (Table 1; Fig. 2). The ASVs were dominated by the phyla Ascomycota, Basidiomycota and Mortierellomycota. In the air sample, ASVs identified as Pseudogymnoascus roseus, Cladosporium sp., Mortierella sp. 1, Pseudogymnoascus sp. 3, Pseudogymnoascus sp. 2, Mortierella fimbricystis, Mortierella gamsii and Penicillium sp. were the most dominant taxa (all with $>1,000$ reads), in rank order. In contrast, 27 fungal ASVs (Cladosporium sp., Pseudogymnoascus roseus, Penicillium sp., Meyerozyma guilliermondii, Lecidea sp., Malassezia restricta, Pseudogymnoascus sp. 3, Hanseniaspora lachancei, Pseudogymnoascus sp. 2, Austroplaca darbishirei, Mortierella gamsii, Malassezia globosa, Rhodotorula diobovata, Mortierella sp. 1, Ascomycota sp., Mortierella fimbricystis, Penicillium polonicum, Lecanorales sp., Thelebolus sp., Lecidea cancriformis, Aspergillus sp., Poaceicola agrostina, Glarea sp., Pseudogymnoascus sp. 1, Mortierella sp. 2, Thelebolus globosus and Lecanora physciella) were present as dominant fungi in snow. A further 177 ASVs (62 in air and 115 in snow) were detected less frequently $(<1,000$ reads) and may represent the rare portion of the fungal assemblages. In addition, 78 ASVs could only be assigned to higher taxonomic levels (phylum, class, order or family). A total of 29,069 sequences from the air and 6,223 from the snow samples were matched with the sequences of 11 unidentified species hypotheses in the list of the top 50 most wanted fungi ${ }^{31}$ with the alignment length longer than 250 bp and $>98 \%$ identity (Suppl. Table 1 ).

Fungal diversity. The Mao Tao rarefaction curves of the fungal assemblages present in air and snow reached asymptote for both fungal assemblages (Fig. 3), indicating that the data provided a good description of the diversity present. In general, both fungal assemblages displayed high diversity, richness, and dominance indices (Table 2). The assemblage present in the snow was more diverse, rich, and included a wider range of dominant fungi when compared with that from the air sample. Of the total fungal ASVs detected, 29 were only present in the air sample and 101 in the snow sample, with 41 present in both samples (Fig. 4a). However, when only the dominant ASVs (>1,000 reads) from both samples were compared, none occurred only in the air (Fig. 4b) and, among the rare portion, 26 occurred in both air and snow (Fig. 4c). In addition, the ecological functional assignments of fungal ASVs in species and genera levels were showed in Suppl. Table 2 and Suppl. Table 3, respectively. 


\begin{tabular}{|c|c|c|c|c|c|}
\hline \multirow[b]{2}{*}{ Hierarchical level } & \multirow[b]{2}{*}{ Fungal taxa (ASVs)* } & \multirow[b]{3}{*}{ Reference sequences } & \multicolumn{2}{|c|}{\begin{tabular}{|l|} 
Reads by \\
Samples
\end{tabular}} & \multirow[b]{2}{*}{ Total } \\
\hline & & & Air & Snow & \\
\hline Fungi & Fungi sp. & & $39^{* *}$ & 20,958 & 20,997 \\
\hline \multirow[t]{53}{*}{ Ascomycota } & Pseudogymnoascus roseus & SH1557165.08FU & 61,935 & 0 & 61,935 \\
\hline & Cladosporium sp. & SH1521536.08FU & 20,801 & 0 & 20,801 \\
\hline & Pseudogymnoascus sp. & SH1557215.08FU & 2,035 & 1,5650 & 17,685 \\
\hline & Meyerozyma sp. & SH1516625.08FU & 0 & 1,5735 & 15,735 \\
\hline & Penicillium sp. & SH1530043.08FU & 431 & 9,385 & 9,816 \\
\hline & Lecidea cancriformis & SH2711223.08FU & 0 & 6,781 & 6,781 \\
\hline & Hanseniaspora sp. & SH1547214.08FU & 0 & 4,708 & 4,708 \\
\hline & Austroplaca darbishirei & SH1633428.08FU & 0 & 3,165 & 3,165 \\
\hline & Thelebolus globosus & SH1647628.08FU & 271 & 1,614 & 1,885 \\
\hline & Helotiales sp. & SH1648813.08FU & 1,075 & 404 & 1,479 \\
\hline & Penicillium polonicum & SH1529888.08FU & 0 & 1,233 & 1,233 \\
\hline & Pseudogymnoascus appendiculatus & SH1939321.08FU & 1138 & 0 & 1,138 \\
\hline & Septoriella sp. & SH1525156.08FU & 0 & 902 & 902 \\
\hline & Lecanora physciella & SH1636780.08FU & 0 & 738 & 738 \\
\hline & Cyberlindnera sp. & SH1648567.08FU & 571 & 0 & 571 \\
\hline & Mitrulinia sp. & SH1574181.08FU & 0 & 482 & 482 \\
\hline & Cleistothelebolus nipigonensis & SH1630064.08FU & 0 & 433 & 433 \\
\hline & Chalara pseudoaffinis & SH1522386.08FU & 368 & 0 & 368 \\
\hline & Pestalotiopsis sp. & SH1562655.08FU & 0 & 364 & 364 \\
\hline & Neoascochyta paspali & SH1547057.08FU & 329 & 4 & 333 \\
\hline & Paraconiothyrium africanum & SH1525457.08FU & 0 & 331 & 331 \\
\hline & Debaryomyces sp. & SH1516581.08FU & 62 & 251 & 313 \\
\hline & Phaeoacremonium hungaricum & SH1644597.08FU & 0 & 287 & 287 \\
\hline & Lecidea sp. & SH1524770.08FU & 0 & 277 & 277 \\
\hline & Colletotrichum sp. & SH1636843.08FU & 186 & 90 & 276 \\
\hline & Rhizoscyphus sp. & SH1543082.08FU & 169 & 103 & 272 \\
\hline & Aspergillus sp. & SH1536361.08FU & 0 & 249 & 249 \\
\hline & Schwanniomyces polymorphus & SH1649127.08FU & 0 & 244 & 244 \\
\hline & Septoriella hirta & SH2714710.08FU & 0 & 225 & 225 \\
\hline & Ascomycota sp. & SH1574206.08FU & 123 & 82 & 205 \\
\hline & Penicillium fluviserpens & SH1536160.08FU & 0 & 199 & 199 \\
\hline & Saccharomyces cerevisiae & SH1583301.08FU & 0 & 193 & 193 \\
\hline & Aspergillus niger & SH3322875.08FU & 0 & 183 & 183 \\
\hline & Volucrispora graminea & SH1605412.08FU & 0 & 154 & 154 \\
\hline & Aspergillus sydowii & SH1550060.08FU & 38 & 113 & 151 \\
\hline & Penicillium steckii & SH1692788.08FU & 0 & 150 & 150 \\
\hline & Leptosphaeria sclerotioides & SH1624038.08FU & 147 & 0 & 147 \\
\hline & Leotiomycetes sp. & SH1647738.08FU & 136 & 0 & 136 \\
\hline & Pseudallescheria sp. & SH2328594.08FU & 0 & 132 & 132 \\
\hline & Buellia russa & SH1551132.08FU & 0 & 130 & 130 \\
\hline & Chaetothyriales sp. & SH1545109.08FU & 0 & 129 & 129 \\
\hline & Penicillium brasilianum & SH1692798.08FU & 0 & 123 & 123 \\
\hline & Phaeosphaeria dennisiana & SH1530704.08FU & 120 & 0 & 120 \\
\hline & Pseudallescheria ellipsoidea & SH2328455.08FU & 0 & 112 & 112 \\
\hline & Lodderomyces elongisporus & SH1507873.08FU & 103 & 0 & 103 \\
\hline & Candida tropicalis & SH1542296.08FU & 101 & 0 & 101 \\
\hline & Yamadazyma sp. & SH1539910.08FU & 101 & 0 & 101 \\
\hline & Trichoderma sp. & SH1542292.08FU & 0 & 91 & 91 \\
\hline & Didymellaceae sp. & SH1547074.08FU & 82 & 0 & 82 \\
\hline & Penicillium paxilli & SH1530009.08FU & 8 & 73 & 81 \\
\hline & Parmeliaceae sp. & SH1541255.08FU & 71 & 0 & 71 \\
\hline & Paraphoma fimeti & SH1616190.08FU & 0 & 70 & 70 \\
\hline & Colletotrichum annellatum & SH2219599.08FU & 0 & 67 & 67 \\
\hline & Polysporina subfuscescens & SH1596449.08FU & 0 & 67 & 67 \\
\hline प्तापा & & & & & \\
\hline
\end{tabular}




\begin{tabular}{|c|c|c|c|c|c|}
\hline \multirow[b]{2}{*}{ Hierarchical level } & \multirow[b]{2}{*}{ Fungal taxa (ASVs)* } & \multirow[b]{3}{*}{ Reference sequences } & \multicolumn{2}{|c|}{\begin{tabular}{|l|} 
Reads by \\
Samples
\end{tabular}} & \multirow[b]{2}{*}{ Total } \\
\hline & & & Air & Snow & \\
\hline \multirow[t]{29}{*}{ Fungi } & Fungi sp. & & $39^{* *}$ & 20,958 & 20,997 \\
\hline & Pseudeurotium sp. & SH3332798.08FU & 67 & 0 & 67 \\
\hline & Dermateaceae sp. & SH1522957.08FU & 66 & 0 & 66 \\
\hline & Penicillium astrolabium & SH1530010.08FU & 0 & 66 & 66 \\
\hline & Cladosporium halotolerans & SH1525346.08FU & 37 & 27 & 64 \\
\hline & Diaporthales sp. & SH1657193.08FU & 64 & 0 & 64 \\
\hline & Lecanoromycetes sp. & SH1517968.08FU & 0 & 60 & 60 \\
\hline & Lecanora contractula & SH1527996.08FU & 0 & 55 & 55 \\
\hline & Ramalinaceae sp. & SH1522446.08FU & 0 & 51 & 51 \\
\hline & Cystodendron sp. & SH1524864.08FU & 50 & 0 & 50 \\
\hline & Penicillium cairnsense & SH2190109.08FU & 0 & 50 & 50 \\
\hline & Cladonia rei & SH3326345.08FU & 49 & 0 & 49 \\
\hline & Neodevriesia capensis & SH3331962.08FU & 0 & 49 & 49 \\
\hline & Neopestalotiopsis sp. & SH3324784.08FU & 49 & 0 & 49 \\
\hline & Penicillium sumatraense & SH1585145.08FU & 9 & 37 & 46 \\
\hline & Mycosphaerella tassiana & SH1607937.08FU & 0 & 44 & 44 \\
\hline & Pseudeurotiaceae sp. & SH1556184.08FU & 44 & 0 & 44 \\
\hline & Fusarium solani & SH2721166.08FU & 43 & 0 & 43 \\
\hline & Placopsis contortuplicata & SH1521544.08FU & 0 & 40 & 40 \\
\hline & Schwanniomyces sp. & SH2154634.08FU & 38 & 0 & 38 \\
\hline & Bacidina arnoldiana & SH3321741.08FU & 0 & 28 & 28 \\
\hline & Penicillium citrinum & SH1539276.08FU & 15 & 13 & 28 \\
\hline & Zymoseptoria verkleyi & SH1544001.08FU & 21 & 0 & 21 \\
\hline & Sarocladium sp. & SH1542060.08FU & 17 & 0 & 17 \\
\hline & Aspergillus penicillioides & SH1537266.08FU & 16 & 0 & 16 \\
\hline & Pichia kluyveri & SH1527730.08FU & 16 & 0 & 16 \\
\hline & Botryosphaeriaceae sp. & SH3317647.08FU & 0 & 6 & 6 \\
\hline & Fusarium asiaticum & SH2456121.08FU & 0 & 4 & 4 \\
\hline & Usnea sp. & SH1550545.08FU & 0 & 3 & 3 \\
\hline \multirow[t]{24}{*}{ Basidiomycota } & Malassezia restricta & SH2734004.08FU & 401 & 4,740 & 5,141 \\
\hline & Malassezia globosa & SH1565779.08FU & 165 & 2,946 & 3,111 \\
\hline & Rhodotorula diobovata & SH1585138.08FU & 0 & 3,060 & 3,060 \\
\hline & Agaricomycetes sp. & SH1575746.08FU & 0 & 2,581 & 2,581 \\
\hline & Malassezia sp. & SH1546915.08FU & 22 & 1,548 & 1,570 \\
\hline & Marasmius sp. & SH1514868.08FU & 912 & 0 & 912 \\
\hline & Rhodotorula mucilaginosa & SH1558606.08FU & 750 & 120 & 870 \\
\hline & Leucosporidiella creatinivora & SH1651377.08FU & 404 & 0 & 404 \\
\hline & Heterochaete shearii & SH1561152.08FU & 75 & 259 & 334 \\
\hline & Malasseziales sp. & SH1547455.08FU & 46 & 266 & 312 \\
\hline & Calyptella capula & SH1635872.08FU & 0 & 170 & 170 \\
\hline & Pluteus ephebeus & SH2724840.08FU & 158 & 0 & 158 \\
\hline & Malassezia equina & SH2723257.08FU & 0 & 95 & 95 \\
\hline & Vishniacozyma victoriae & SH1572254.08FU & 94 & 0 & 94 \\
\hline & Phanerochaete sordida & SH1573517.08FU & 83 & 0 & 83 \\
\hline & Hyphodontia microspora & SH1651385.08FU & 82 & 0 & 82 \\
\hline & Peniophora laxitexta & SH1646415.08FU & 56 & 0 & 56 \\
\hline & Gymnopus sp. & SH1560298.08FU & 50 & 0 & 50 \\
\hline & Vishniacozyma tephrensis & SH1691243.08FU & 48 & 0 & 48 \\
\hline & Microbotryomycetes sp. & SH2750674.08FU & 40 & 0 & 40 \\
\hline & Vanrija humicola & SH1514178.08FU & 30 & 0 & 30 \\
\hline & Basidiomycota sp. & SH1514435.08FU & 0 & 19 & 19 \\
\hline & Polyporales sp. & SH1651381.08FU & 15 & 0 & 15 \\
\hline & Malassezia sympodialis & SH3313592.08FU & 0 & 12 & 12 \\
\hline \multirow[t]{2}{*}{ Mortierellomycota } & Mortierella sp. & SH1557435.08FU & 5,878 & 744 & 6,622 \\
\hline & Mortierella fimbricystis & SH2452854.08FU & 2,260 & 0 & 2,260 \\
\hline Continued & & & & & \\
\hline
\end{tabular}




\begin{tabular}{|c|c|c|c|c|c|}
\hline \multirow[b]{2}{*}{ Hierarchical level } & \multirow[b]{2}{*}{ Fungal taxa (ASVs)* } & \multirow[b]{3}{*}{ Reference sequences } & \multicolumn{2}{|c|}{\begin{tabular}{|l|} 
Reads by \\
Samples
\end{tabular}} & \multirow[b]{2}{*}{ Total } \\
\hline & & & Air & Snow & \\
\hline Fungi & \begin{tabular}{|l} 
Fungi sp. \\
\end{tabular} & & $39^{* *}$ & 20,958 & 20,997 \\
\hline & Mortierella gamsii & SH1556972.08FU & 1,416 & 155 & 1,571 \\
\hline & Mortierella parvispora & SH1629873.08FU & 396 & 0 & 396 \\
\hline & Mortierella alpina & SH1503809.08FU & 158 & 0 & 158 \\
\hline & Mortierella elongatula & SH1574597.08FU & 0 & 74 & 74 \\
\hline & Mortierella turficola & SH3338068.08FU & 0 & 56 & 56 \\
\hline Mucoromycota & Densospora sp. & SH3319965.08FU & 0 & 145 & 145 \\
\hline
\end{tabular}

Table 1. Numbers of sequence reads of fungal amplicon sequence variants (ASVs) detected in air and snow samples from Livingston Island, South Shetlands, Antarctica. ${ }^{\star}$ ASVs = amplicon sequence variants; ${ }^{* *}$ number of the reads.

$\mathbf{a}$

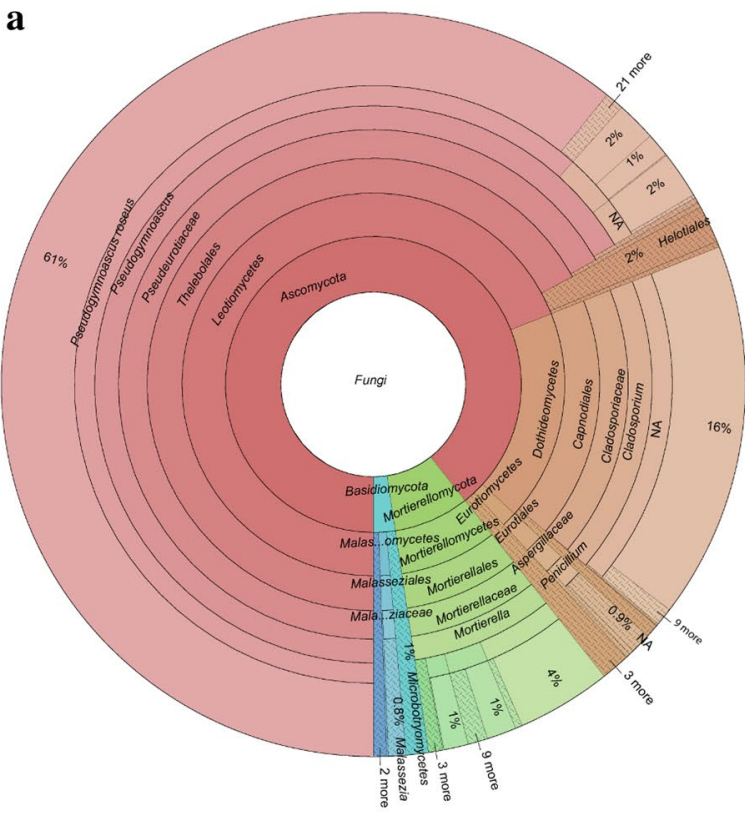

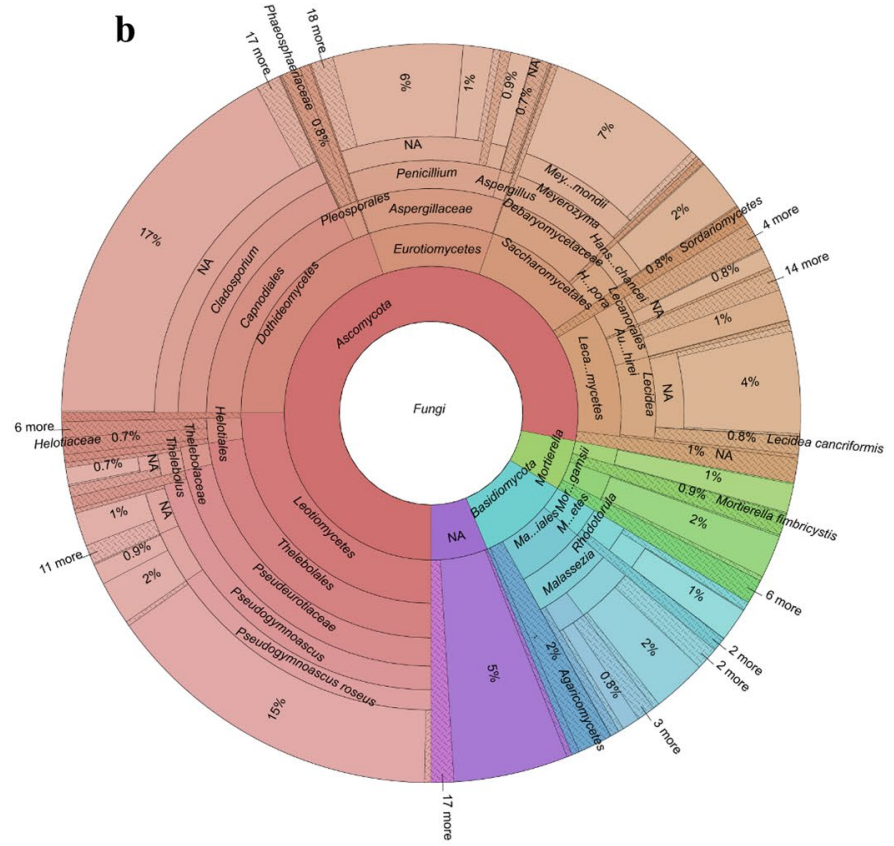

Figure 2. Krona chart of (a) fungal assemblages detected in the air and (b) in snow from Livingston Island, South Shetland Islands, Antarctica.

a

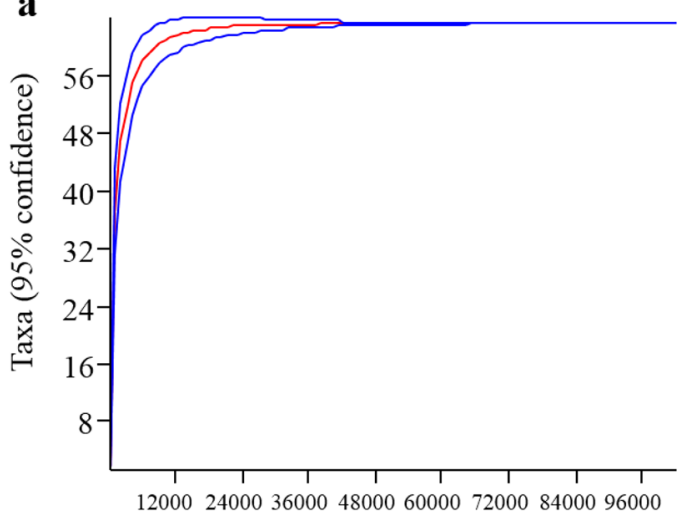

Specimens

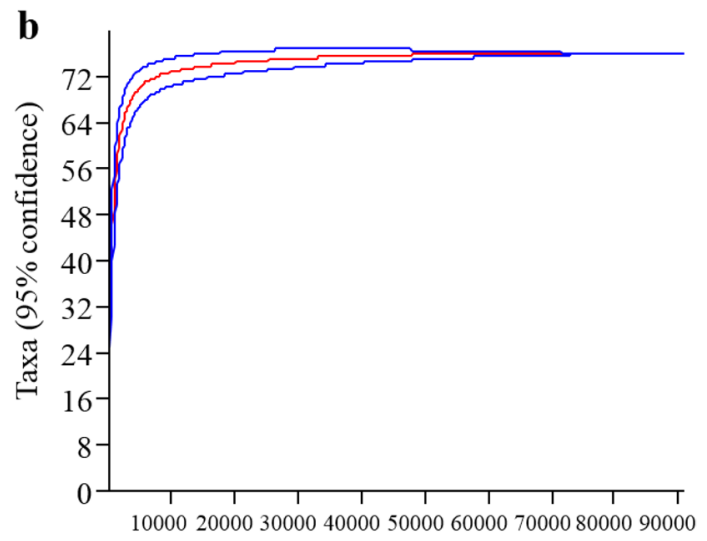

Specimens

Figure 3. Rarefaction curves for samples from fungal assemblages present in the (a) air and (b) snow on Livingston Island, South Shetlands, Antarctica. Blue lines represent confidence limits inferred using bootstrap values calculated from 1,000 iterations using PAST, version $1.90^{34}$. 


\begin{tabular}{|l|l|l|l|}
\hline \multirow{2}{*}{ Ecological indices } & \multicolumn{3}{|l|}{ Sample } \\
\cline { 2 - 4 } & Air & Snow & Total \\
\hline Number of reads & 162,038 & 268,710 & 430,748 \\
\hline Number of taxa & 70 & 142 & 171 \\
\hline Fisher $\alpha$ & 6.96 & 14.44 & 16.85 \\
\hline Margalef & 5.75 & 11.3 & 13 \\
\hline Simpson & 0.6 & 0.92 & 0.85 \\
\hline
\end{tabular}

Table 2. Sample data and ecological indices of the fungal DNA recovered from air and snow samples from Livingston Island, South Shetlands, Antarctica.

$\mathbf{a}$
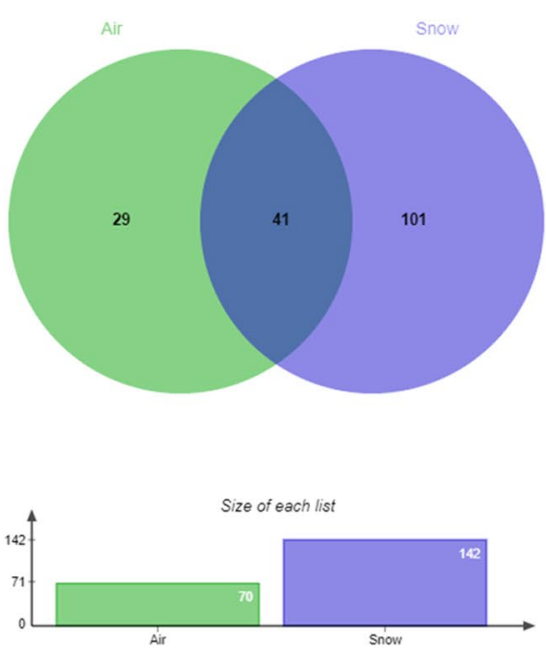

b
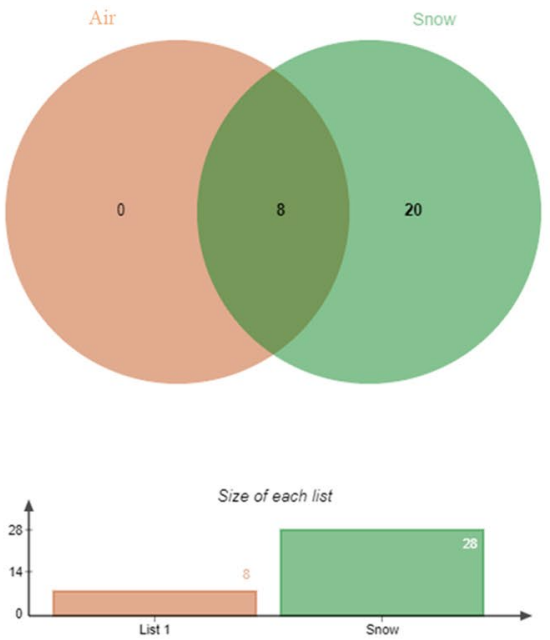

c
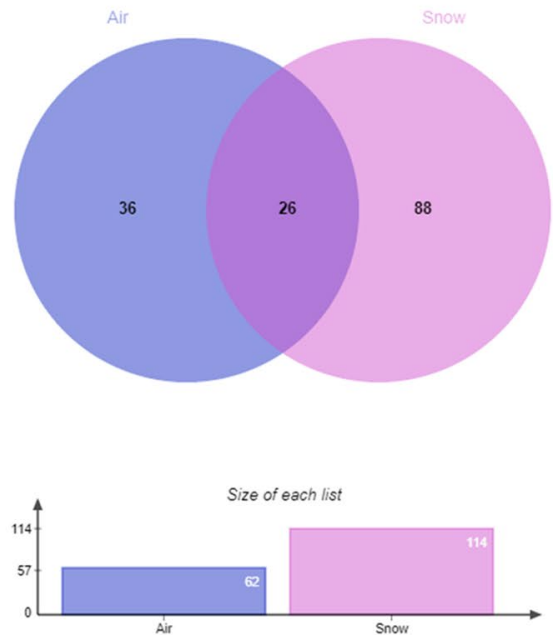

Figure 4. (a) Venn diagram showing the (a) total, (b) dominant (those with $>1,000$ reads) and (c) rare fungal taxa distribution detected in air and snow of Livingston Island, South Shetlands, Antarctica.

\section{Discussion}

Fungal taxonomy and diversity. Despite an increase in mycological studies, fungal diversity in Antarctica remains poorly known ${ }^{11}$. According to Bridge and Spooner ${ }^{37}$, around 1,000 fungal species have been described from Antarctica, identified using a range of approaches including traditional methods for cultivable fungi such as macro- and/or micromorphology of colonies and fruiting bodies as well as DNA sequencing of mycelia of cultivable fungi. Most airborne mycological studies in Antarctica have relied on traditional morphological methods. Marshall ${ }^{4}$ monitored airborne fungal spores over 13.6 months at three sites on Signy Island (South Orkney Islands) in the maritime Antarctic, reporting that Epicoccum spp. and Cladosporium spp. dominated the diversity present. Duncan et al. ${ }^{38}$ sampled air inside the historic wooden huts on Ross Island, finding Cladosporium cladosporioides, Pseudeurotium desertorum, Pseudogymnoascus sp. and Antarctomyces psychrotrophicus as dominant viable fungal propagules and Cadophora sp. and Thebolus sp. as minor components of the outdoor airborne fungal assemblage. Archer et al. $^{2}$ compared microbial diversity in near-ground and highaltitude air above the Victoria Land Dry Valleys as well as that of underlying soil microbial communities, finding basidiomycete yeasts to be dominant in the air and unclassified fungi to be common in soils. However, the more recent fungal inventories using metabarcoding approaches have demonstrated that fungal diversity in Antarctica is greater than previously recognised ${ }^{39-41}$.

As air and snow are typically ultra-oligotrophic microhabitats, few viable fungal taxa are expected to be present, as reported by de Menezes et al. ${ }^{12}$ who, using cultivation techniques, reported only 14 fungal taxa in snow samples from several different Antarctic islands. However, despite analysing only a small a small absolute sample size of air and snow collected in the Livingston Island, use of the HTS approach in the current study revealed the presence of much greater fungal diversity in both air and snow, many of which display mechanisms that render them well-adapted to survive atmospheric transport, such as the production of resistant spores and UV protective compounds $s^{42,43}$.

The dominant taxa detected in the air included representatives of Pseudogymnoascus, Cladosporium, Mortierella and Penicillium. However, even though recently deposited snow would be expected to contain microbial airborne particles entrained from the air column as the snow fell, fungal diversity in the snow sampled was very different to that in the air over the same location. In snow sample, the dominant taxa found included representatives of Cladosporium, Pseudogymnoascus, Penicillium, Meyerozyma, Lecidea, Malassezia, Hanseniaspora, Austroplaca, Mortierella, Rhodotorula, Penicillium, Thelebolus, Aspergillus, Poaceicola, Glarea and Lecanora. The 
diversity present in both the air and snow samples also included dominant taxa that could only be assigned to higher taxonomic levels such as Fungal sp., Ascomycota sp., Basidiomycota sp., Agaricales sp., Chaetothyriales sp., Helotiales sp., Lecanorales sp. and Polyporales sp. These may represent currently undescribed or otherwise unsequenced species, further supporting the assertion that much of the true fungal diversity present in Antarctica is currently unknown.

Pseudogymnoascus were detected as dominant fungi in both air and snow samples. Pseudogymnoascus (previously known as Geomyces) is a genus often detected in cold environments including those of polar, alpine, and temperate regions ${ }^{11,44-47}$. In Antarctica, it has been reported from soils ${ }^{44,48-50}$, associated with plants ${ }^{51-54}$ and macroalgae ${ }^{55}$, in freshwater lakes ${ }^{56}$, and associated with lichens ${ }^{57}$. Cladosporium and Penicillium also represent common airborne fungi reported globally, including Antarctica. Cladosporium is a dematiaceous fungal group with global distribution ${ }^{58}$. In Antarctic microhabitats, Cladosporium has mainly been detected in association with plants and soil ${ }^{11}$. Penicillium is a ubiquitous genus, again detected in multiple substrates in Antarctica including soils $s^{50,59,60}$, permafrost ${ }^{61,62}$ and associated with macroalgae ${ }^{63}$. The abundant presence of Pseudogymnoascus, Cladosporium, and Penicillium both in air and snow sampled indicated that these fungi may circulate at least around the Antarctic Peninsula.

The genus Mortierella includes about 85 species, which occur mainly in soils ${ }^{64}$. Mortierella species are found worldwide, particularly in temperate and polar regions. Representatives of the genus are abundant in Antarctica and reported in association with plant ${ }^{51,52}$, macroalgae ${ }^{63}$, lichens ${ }^{57}$, soils ${ }^{65}$, freshwater ${ }^{56}$, and permafrost ${ }^{62}$. Some species of Mortierella are known as snow moulds and have the capability to growth and produce spores at $0^{\circ} \mathrm{C}^{66}$. They occur abundantly in the interstitial water in Antarctic snow where snow melting occurs in summer, for instance in association with snow algal communities.

The genus Malassezia includes 17 species of basidiomycetous pigmented black yeast species generally present in the skin and mucosa microbiome of humans and other warm-blooded animals ${ }^{67}$. According to Prohic et al. ${ }^{68}$, several Malassezia species found on human and animal skin are commensals, but they can also be associated with Pityriasis versicolor, Malassezia folliculitis, seborrheic dermatitis/dandruff, atopic dermatitis, and psoriasis. The detection of Malassezia in Antarctica is unusual. Rosa et al. ${ }^{54}$ detected different Malassezia taxa in soil samples from undisturbed and disturbed (by human activity) sites on Deception Island (South Shetland Islands) using HTS metabarcoding techniques.

The genus Meyerozyma includes species that are typically widely distributed or cosmopolitan ${ }^{69}$. Species of Meyerozyma have previously been isolated from aquatic environments in Antarctica ${ }^{69,70}$ and associated with macroalgae ${ }^{63}$. The genus Hanseniaspora (anamorph Kloeckera) includes ascomycete yeast species commonly associated with alcoholic fermentation, but is also recorded from soil, plants, fruit-eating insects, birds, and seafood ${ }^{71}$. Some Hanseniaspora species have been reported as unusual opportunistic superficial mycosis in humans ${ }^{72-75}$.

The genus Rhodotorula includes cosmopolitan pigmented yeast species and is often dominant in extreme environments ${ }^{76}$, including those of Antarctica ${ }^{63,70}$. Our study represents the first report of high abundance of $R$. muscilagionsa in Antarctic snow samples, although de Menezes et al. ${ }^{13}$ reported the species among the dominant fungi detected in snow samples from several Antarctic islands. The genus Thelebolus is distributed globally and representatives occur in diverse habitats ${ }^{77}$. Species of Thelebolus have been reported in Arctic and Antarctic environments ${ }^{78,79}$, as being abundant in lakes, and in association with birds (skuas) ${ }^{80}$, in freshwater ${ }^{56,81}$ and in ice $^{15}$. Finally, from the air and snow sampled in Livingston Island, Antarctica, we detected 11 unidentified species hypotheses in the list of the top 50 most wanted fungi ${ }^{31}$, suggesting the both habitats may shelter rare species that merit further taxonomic attention.

\section{Conclusions}

We used DNA metabarcoding to catalogue the fungi present in air and snow samples from Livingston Island, South Shetland Islands. This revealed a diverse fungal community comprising taxa from the phyla Ascomycota, Basidiomycota, Mortierellomycota and Mucoromycota. The assemblages were dominated by cold-adapted and cosmopolitan (psychrophilic) taxa, including members of the genera Pseudogymnoascus, Malassezia and Rhodotorula, which include taxa reported as opportunistic fungi. Our results confirm the presence of fungi in the airspora, supporting the possibility of dispersal over different geographical scales around Antarctica in the air column. Given that many of the taxa identified in this study are known from Antarctic fungal communities, a local source for those present in the air column is plausible. The large proportion of unassigned taxa highlight the poor level of baseline knowledge of Antarctic fungal diversity, and further aeromicrobiology and diversity studies are required to understand the dynamics of fungal dispersal within and beyond Antarctica. However, as metabarcoding detects environmental DNA, the technique can also detect DNA from dead fungi or otherwise non-viable material. Further studies will be necessary to develop strategies to isolate these fungi into culture.

Received: 22 August 2020; Accepted: 19 November 2020

Published online: 11 December 2020

\section{References}

1. Siegert, M. J. et al. Recent advances in understanding Antarctic climate evolution. Antarct. Sci 4, 313-325 (2008).

2. Archer, S. D. J. et al. Airborne microbial transport limitation to isolated Antarctic soil habitats. Nat. Microbiol. 4, 925-932 (2019).

3. Marshall, W. A. Aerial dispersal of lichen soredia in the maritime Antarctic. New Phytol. 134, 523-530 (1996).

4. Marshall, W. A. Seasonality in Antarctic airborne fungal spores. Appl. Environ. Microbiol. 63, 2240-2245 (1997).

5. Hughes, K. A. et al. A preliminary study of airborne microbial biodiversity over peninsular Antarctica. Cell. Mol. Biol. 50, 537-542 (2004).

6. Vincent, W. F. Evolutionary origins of Antarctic microbiota: invasion, selection and endemism. Antarct. Sci. 12, 374-385 (2000). 
7. Pearce, D. A. et al. Biodiversity of airborne microorganisms at Halley Station, Antarctica. Extremophiles 14, 145-159 (2010).

8. Bottos, E. M. et al. Airborne bacterial populations above desert soils of the McMurdo Dry Valleys, Antarctica. Microb. Ecol. 67, $120-128$ (2014).

9. Pearce, D. A. et al. Aerobiology over Antarctica - A new initiative for atmospheric ecology. Front. Microbiol. 16, 7-16 (2016).

10. Womack, A. M., Bohannan, B. J., and Green, J. L. Biodiversity and biogeography of the atmosphere. Philos. Trans. R. Soc. B Biol. Sci. 365, 3645-3653 (2010).

11. Rosa, L.H. et al. Fungi in Antarctica: diversity, ecology, effects of climate change, and bioprospection for bioactive compounds in Fungi of Antarctica: Diversity, Ecology and Biotechnological Applications (ed. Rosa, L.H.) 1-18 (2019).

12. de Menezes, G.C.A. et al. Fungi in snow and glacial ice of Antarctica in Fungi of Antarctica: Diversity, Ecology and Biotechnological Applications (ed. Rosa, L.H.) 127-146 (2019a).

13. de Menezes, G. C. A. et al. Diversity, distribution, and ecology of fungi in the seasonal snow of Antarctica. Microorganisms 7, 445 (2019).

14. Rogers, S. O. et al. Comparisons of protocols for decontamination of environmental ice samples for biological and molecular examinations. Appl. Environ. Microbiol. 70, 2540-2544 (2004).

15. de Menezes, G. C. A. et al. Fungi in glacial ice of Antarctica: diversity, distribution and bioprospecting of bioactive compounds. Extremophiles 24, 367-376 (2020).

16. Šantl-Temkiv, T. et al. High-flow-rate impinger for the study of concentration, viability, metabolic activity, and ice-nucleation activity of airborne bacteria. Environ. Sci. Technol. 51, 11224-11234 (2017).

17. Šantl-Temkiv, T. et al. Aeolian dispersal of bacteria in southwest Greenland: their sources, abundance, diversity and physiological states. FEMS Microbiol. Ecol. 94, 10.1093 (2018).

18. Lever, M. A. et al. A modular method for the extraction of DNA and RNA, and the separation of DNA pools from diverse environmental sample types. Front. Microbiol. 6, 476 (2015).

19. Chen, S. et al. Validation of the ITS2 region as a novel DNA barcode for identifying medicinal plant species. PLoS ONE 5, e8613 (2010).

20. Richardson, R. T. et al. Application of ITS2 metabarcoding to determine the provenance of pollen collected by honey bees in an agroecosystem. Appl. Plant Sci. 3, 1400066 (2015).

21. White, T.J. et al. Amplification and direct sequencing of fungal ribosomal RNA genes for phylogenetics in PCR Protocols: a guide to methods and applications (ed. Innis, M.A., Gelfand, D.H., Sninsky, J.J., White, T.J.) 315-322 (1990).

22. Joshi, N.A., Fass, J.N. Sickle: A sliding-window, adaptive, quality-based trimming tool for FastQ files (Version 1.33) [Software]. https://github.com/najoshi/sickle (2011).

23. Bolyen, E. et al. Reproducible, interactive, scalable and extensible microbiome data science using QIIME 2. Nat. Biotechnol. 37, 852-857 (2019).

24. Callahan, B. J. et al. DADA2: high-resolution sample inference from Illumina amplicon data. Nat. Methods 13, 581-583 (2016).

25. Bokulich, N. A. et al. Optimizing taxonomic classification of marker-gene amplicon sequences with QIIME 2's q2-feature-classifier plugin. Microbiome 6, 90 (2018).

26. Abarenkov, K. et al. UNITE QIIME release for eukaryotes. Version 04.02.2020. UNITE Community. https://doi.org/10.15156/ $\mathrm{BIO} / 786386$ (2020).

27. Medinger, R. et al. Diversity in a hidden world: potential and limitation of next-generation sequencing for surveys of molecular diversity of eukaryotic microorganisms. Mol. Ecol. 19, 32-40 (2010).

28. Weber, A. A. \& Pawlowski, J. Can abundance of protists be inferred from sequence data: a case study of Foraminifera. PLoS ONE 8, e56739 (2013).

29. Giner, C. R. et al. Environmental sequencing provides reasonable estimates of the relative abundance of specific picoeukaryotes. Appl. Environ. Microbiol. 82, 4757-4766 (2016).

30. Hering, D. et al. Implementation options for DNA-based identification into ecological status assessment under the European Water Framework Directive. Water Res. 138, 192-205 (2018).

31. Nilsson, R. H. et al. Top 50 most wanted fungi. Myco-Keys 12, 29-40 (2016).

32. Edgar, R. C. Search and clustering orders of magnitude faster than BLAST. Bioinformatics 26, 2460-2461 (2010).

33. Abarenkov, K. et al. UNITE general FASTA release for Fungi. Version 04.02.2020. UNITE Community. https://doi.org/10.15156/ $\mathrm{BIO} / 786368(2020)$.

34. Hammer, Ø., Harper, D. A. T. \& Ryan, P. D. PAST: paleontological statistics software package for education and data analysis. Palaeontol. Electron. 4, 9 (2001).

35. Bardou, P. et al. An interactive Venn diagram viewer. BMC Bioinform. 15, 293 (2014).

36. Nguyen, N. H. et al. FUNGuild: an open annotation tool for parsing fungal community datasets by ecological guild. Fungal Ecol. 20, 241-248 (2016).

37. Bridge, P. D. \& Spooner, B. M. Non-lichenized Antarctic fungi: Transient visitors or members of a cryptic ecosystem?. Fungal Ecol. 5, 381-394 (2012).

38. Duncan, S. M. et al. Monitoring and identification of airborne fungi at historic locations on Ross Island, Antarctica. Polar Sci. 4, 275-283 (2010).

39. Baeza, M. et al. Amplicon-metagenomic analysis of fungi from Antarctic terrestrial habitats. Front. Microbiol. 8, 2235 (2017).

40. Durán, P. et al. Occurrence of soil fungi in Antarctic pristine environments. Front. Bioeng. Biotechnol. 7, 28 (2019).

41. Rosa, L.H. et al. DNA metabarcoding high-throughput sequencing uncovers cryptic fungal diversity in soils of protected and non-protected areas on Deception Island, Antarctica. Sci. Rep. Submitted (2020).

42. Robinson, C. H. Cold adaptation in Arctic and Antarctic fungi. New Phytol. 151, 341-353 (2001).

43. Braga, G. U. L. et al. Molecular and physiological effects of environmental UV radiation on fungal conidia. Curr. Genet. 61, 405-425 (2015).

44. Mercantini, R., Marsella, R. \& Cervellati, M. C. Keratinophilic fungi isolated from Antarctic soil. Mycopathologia 106, 47-52 (1989).

45. Lorch, J. M. et al. A culture-based survey of fungi in soil from bat hibernacula in the eastern United States and its implications for detection of Geomyces destructans, the causal agent of bat white-nose syndrome. Mycologia 105, 237-252 (2013).

46. Minnis, A.M., Lindner, D.L. Phylogenetic evaluation of Geomyces and allies reveals no close relatives of Pseudogymnoascus destructans, comb. nov., in bat hibernacula of eastern North America. Fungal Biol. 117, 638-649 (2013).

47. Ali, S. H. et al. Studies on diversity of soil microfungi in the Hornsund area, Spitsbergen. Pol. Res. 35, 203-224 (2014).

48. Arenz, B. E. \& Blanchette, R. A. Distribution and abundance of soil fungi in Antarctica at sites on the Peninsula, Ross Sea Region and McMurdo Dry Valleys. Soil Biol. Biochem. 43, 308-315 (2011).

49. Krishnan, A. et al. Extracellular hydrolase enzyme production by soil fungi from King George Island, Antarctica. Polar Biol. 34, 1535-1542 (2011).

50. Gomes, E. C. et al. Cultivable fungi present in Antarctic soils: taxonomy, phylogeny, diversity, and bioprospecting of antiparasitic and herbicidal metabolites. Extremophiles 22, 381-393 (2018).

51. Tosi, S., Casado, B. \& Gerdol, R. Fungi isolated from Antarctic mosses. Polar Biol. 25, 262-268 (2002),

52. Rosa, L.H. et al. Endophytic fungi community associated with the dicotyledonous plant Colobanthus quitensis (Kunth) Bartl. (Caryophyllaceae) in Antarctica. FEMS Microbiol. Ecol. 73, 178-189 (2010). 
53. Carvalho, C. R. et al. Fungi associated with the briosphere of the bipolar mosses Polytrichastrum alpinum and Polytrichum juniperinum in Antarctica. Polar Biol. 43, 545-553 (2020).

54. Rosa, L. H. et al. Opportunistic fungal assemblages present on fairy rings spread on different moss species in the Antarctic Peninsula. Polar Biol. 43, 587-596 (2020).

55. Loque, C. P. et al. Fungal community associated with marine macroalgae from Antarctica. Polar Biol. 33, 641-648 (2010).

56. Gonçalves, V. N. et al. Diversity and distribution of fungal communities in lakes of Antarctica. FEMS Microbiol. Ecol. 82, 459-471 (2012).

57. Santiago, I. F. et al. Lichenosphere: a protected natural microhabitat of the non-lichenised fungal communities living in extreme environments of Antarctica. Extremophiles 19, 1087-1097 (2015).

58. Bensch, K. et al. Species and ecological diversity within the Cladosporium cladosporioides complex (Davidiellaceae, Capnodiales). Stud. Mycol. 67, 1-94 (2010).

59. McRae, C. F., Hocking, A. D. \& Seppelt, R. D. Penicillium species from terrestrial habitats in the Windmill Islands, East Antarctica, including a new species, Penicillium antarcticum. Polar Biol. 21, 97-111 (1999).

60. Godinho, V. M. et al. Diversity and bioprospection of fungal community present in oligotrophic soil of continental Antarctica. Extremophiles 19, 585-596 (2015).

61. Zucconi, L. et al. Searching for eukaryotic life preserved in Antarctic permafrost. Polar Biol. 35, 749-757 (2012).

62. Silva, T. H. et al. Diversity, distribution, and ecology of viable fungi in permafrost and active layer of Maritime Antarctica. Extremophiles 24, 565-576 (2020).

63. Godinho, V. M. et al. Diversity and bioprospecting of fungal communities associated with endemic and cold-adapted macroalgae in Antarctica. ISME J. 7, 1434-1451 (2013).

64. Kirk, P.M., Cannon, P.F., Minter, D.W., Stalpers, J.A. Dictionary of the Fungi, 10th ed., CAB International, Wallingford, UK, p. 784 (2008).

65. Bridge, P. D. \& Newsham, K. K. Soil fungal community composition at Mars Oasis, a southern maritime Antarctic site, assessed by PCR amplification and cloning. Fungal Ecol. 2, 66-74 (2009).

66. Onofri, S. et al. Antarctic microfungi as models for exobiology. Planet Space Sci. 52, 229-237 (2004).

67. Theelen, B. et al. Malassezia ecology, pathophysiology, and treatment. Med. Mycol. 56, S10-S25 (2018).

68. Prohic, A. et al. Malassezia species in healthy skin and in dermatological conditions. Int. J. Dermatol. 55, 494-504 (2016).

69. Brandão, L. R. et al. Diversity and biogeographical patterns of yeast communities in Antarctic, Patagonian and tropical lakes. Fungal Ecol. 28, 33-43 (2017).

70. Vaz, A. B. M. et al. The diversity, extracellular enzymatic activities and photoprotective compounds of yeasts isolated in Antarctica. Braz. J. Microbiol. 42, 937-947 (2011).

71. Kurtzman, C., Fell, J.W., Boekhout, T. The Yeasts: A taxonomic study, 5th ed., Elsevier: Amsterdam, The Netherlands, p. 2354 (2011).

72. Emmanouil-Nikoloussi, E. et al. Hanseniaspora uvarum the ultrastructural morphology of a rare ascomycete, isolated from oral thrush. Bull. Group Int. Rech. Sci. Stomatol. Odontol. 37, 13-7 (1994).

73. García-Martos, P. et al. Isolation of Hanseniaspora uvarum (Kloeckera apiculata) in humans. Mycopathologia 144, 73-75 (1999).

74. Severo-Gomes, B.S. et al. Pathogenic characteristics of yeasts isolated from vaginal secretion preserved under mineral oil. J Venom Anim. Toxins Incl. Trop. Dis. 17, 460-6 (2011).

75. Jankowski, M. et al. Hand dermatitis with Hanseniaspora uvarum as a plausible causative agent. Adv. Dermatol. Allergol. XXXV, 641-643 (2018).

76. Margesin, R. et al. Rhodotorula psychrophila sp. nov., Rhodotorula psychrophenolica sp. nov. and Rhodotorula glacialis sp. nov., novel psychrophilic basidiomycetous yeast species isolated from alpine environments. Int. J. Syst. Evol. Microbiol. 57, 2179-2184 (2007).

77. Crous, P. W. et al. MycoBank: an online initiative to launch mycology into the 21st century. Stud. Mycol. 50, 19-22 (2004).

78. Kobayasi, Y. et al. Mycological studies of the Alaskan Arctic. Annu Rep. Inst. Ferment. Osaka 3, 1-138 (1967).

79. Montemartini, A., Caretta, G. \& Del Frate, G. Notes on Thelebolus microsporus isolated in Antarctica. Mycotaxon 48, 343-358 (1993).

80. de Hoog, G. S. et al. Evolution, taxonomy and ecology of the genus Thelebolus in Antarctica. Stud. Mycol. 51, 33-76 (2005).

81. Brunati, M. et al. Diversity and pharmaceutical screening of fungi from benthic mats of Antarctic lakes. Mar. Gen. 2, 43-50 (2009).

\section{Acknowledgements}

This study received financial support from CNPq, PROANTAR, FAPEMIG, Coordenação de Aperfeiçoamento de Pessoal de Nível Superior-Brasil (CAPES), and INCT Criosfera 2. P. Convey is supported by NERC core funding to the British Antarctic Survey's 'Biodiversity, Evolution and Adaptation' Team. We are also grateful for the generous support of the Spanish Polar Committee and its staff at Gabriel de Castilla base. PEASC also thanks congresswoman Jô Moraes. Finally, we appreciate the valuable suggestions of anonymous reviewers.

\section{Author contributions}

L.H.R., P.E.A.S.C., T.S. conceived the study. L.H.R. and P.E.A.S.C. performed DNA extraction from snow and air. L.H.R., P.E.A.S.C., O.H.B.P., T.S., P.C., M.C.S., and C.A.R. analyzed the results and wrote the manuscript. All authors read and approved the final manuscript.

\section{Competing interests}

The authors declare no competing interests.

\section{Additional information}

Supplementary Information The online version contains supplementary material available at https://doi. org/10.1038/s41598-020-78630-6.

Correspondence and requests for materials should be addressed to L.H.R.

Reprints and permissions information is available at www.nature.com/reprints.

Publisher's note Springer Nature remains neutral with regard to jurisdictional claims in published maps and institutional affiliations. 
(c) (i) Open Access This article is licensed under a Creative Commons Attribution 4.0 International cc) License, which permits use, sharing, adaptation, distribution and reproduction in any medium or format, as long as you give appropriate credit to the original author(s) and the source, provide a link to the Creative Commons licence, and indicate if changes were made. The images or other third party material in this article are included in the article's Creative Commons licence, unless indicated otherwise in a credit line to the material. If material is not included in the article's Creative Commons licence and your intended use is not permitted by statutory regulation or exceeds the permitted use, you will need to obtain permission directly from the copyright holder. To view a copy of this licence, visit http://creativecommons.org/licenses/by/4.0/.

(C) The Author(s) 2020 